\title{
Recurrence of pericarditis after influenza vaccination: a case report and review of the literature
}

\author{
Riccardo Mei ${ }^{1}$, Emanuel Raschi ${ }^{1}$, Elisabetta Poluzzi ${ }^{1}$, Igor Diemberger ${ }^{2^{*}}$ (D) and Fabrizio De Ponti ${ }^{1}$
}

\begin{abstract}
Background: This case report describes a patient with pericarditis likely attributed to influenza vaccination (positive rechallenge), with a literature review.

Case presentation: A 87-year old patient developed pericarditis after influenza vaccination, with acute chest pain, without ECG abnormalities or increased cardiac enzyme levels. Echocardiogram showed moderate pericardial effusion. Recovery was obtained through steroids One year later, few days after re-immunization, the patient experienced the same symptoms and was admitted to hospital with diagnosis of recurrence of pericarditis with severe pericardial effusion, again treated with steroids. Other possible causes were ruled out and the cardiologist recommended against influenza vaccinations in the future; the patient did not experience recurrence of pericarditis in the following 6 years. Cases of pericarditis following influenza immunization in the literature were also reviewed.

Conclusions: Pericarditis following immunization for influenza is very rarely reported in the literature. In a few cases, influenza vaccination seems likely responsible. We suggest considering recent immunization in patient's history as part of the differential diagnosis in elderly with chest pain.
\end{abstract}

Keywords: Pericarditits, Rechallenge, Adverse event following immunization, Influenza vaccine, Case report

\section{Background}

Cardiac complications after immunization are extremely rare events, albeit clinically important. In the past, the association between an increased risk of myocarditis and the use of smallpox vaccine, both in military personnel and civilians, drew the attention of clinicians and regulators [1]. Cases of myocarditis, pericarditis or myopericarditis after other vaccines, including multiple immunization have been reported as well, but a definite association was never demonstrated [2-4]. Here below, we describe a case of established pericarditis in an elderly patient following seasonal influenza vaccine with unintentional re-challenge. A 6-year follow-up free of vaccine is also reported. A MEDLINE review was also performed in February 2017 to discuss published case reports/series.

\footnotetext{
* Correspondence: igor.diemberger@unibo.it

${ }^{2}$ Department of Experimental, Diagnostic and Specialty Medicine, Alma

Mater Studiorum-University of Bologna, 40126 Bologna, Italy

Full list of author information is available at the end of the article
}

\section{Case presentation}

On September 2008 a 87-year-old man was admitted to hospital with diffuse, worsening (especially at night) chest pain for several days (Fig. 1). His past history included thyroidectomy, acute myocardial infarction and total atrioventricular block with sick sinus syndrome for which a single-chamber pacemaker was implanted and subsequently upgraded to dual-chamber pacemaker (because of pacemaker syndrome). He was also affected by chronic obstructive pulmonary disease (no treatment reported) and mild chronic kidney failure. Five months before (April 2008) he had been admitted to hospital for worsening heart failure due to acute pneumonia; atrial fibrillation also had occurred and warfarin was started.

In the emergency department, physical examination revealed diminished heart sounds, while chest X-rays showed cardiomegaly. No ECG abnormalities or increased cardiac enzyme levels were found. The primary diagnosis was heart failure due to coronary insufficiency and nitroglycerin provided rapid relief.

(c) The Author(s). 2018 Open Access This article is distributed under the terms of the Creative Commons Attribution 4.0 International License (http://creativecommons.org/licenses/by/4.0/), which permits unrestricted use, distribution, and 


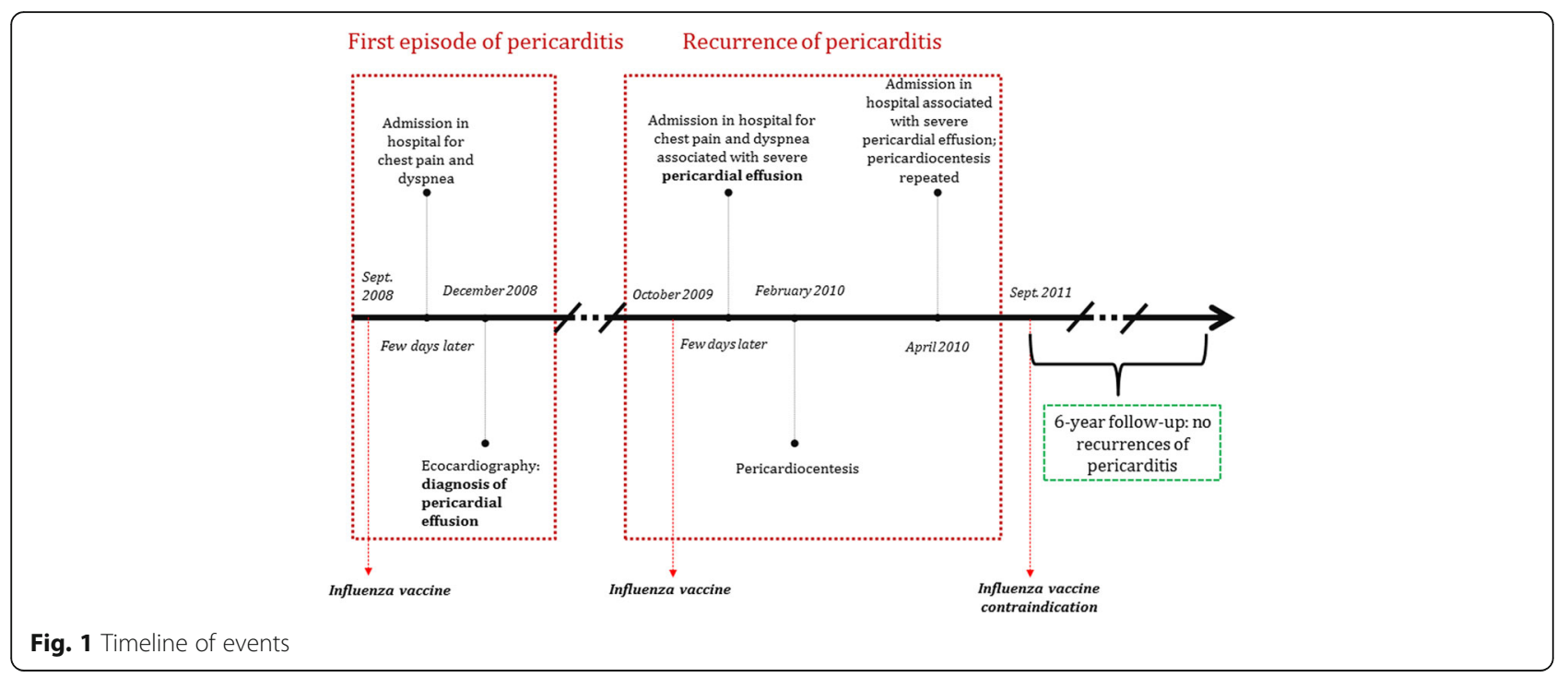

Three months later (December 2008), in a follow-up visit echocardiogram showed moderate pericardial effusion without signs of tamponade (Fig. 2). Steroid therapy (prednisone $40 \mathrm{mg} /$ day with tapering for 1 month) was initiated because of colchicine-related gastrointestinal

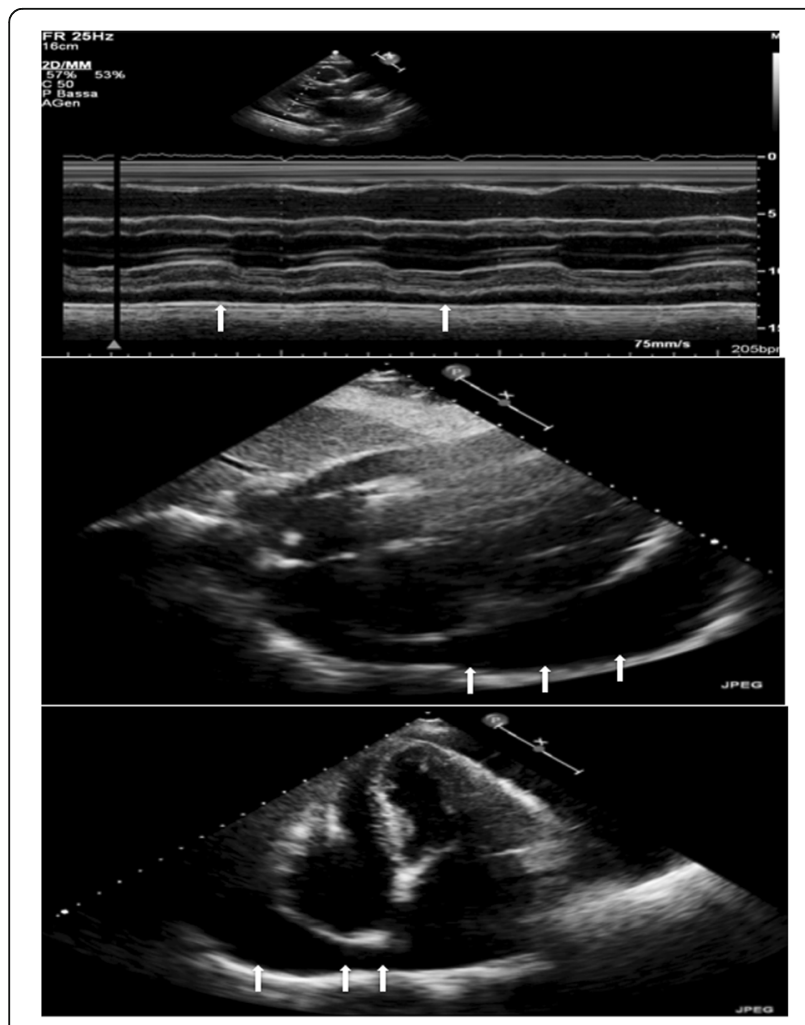

Fig. 2 Transthoracic echocardiogram (M-Mode, subcostal four-chamber and apical four-chamber view) showing moderate pericardial effusion (arrows) toxicity (discontinued early after first administration). T. pallidum immunoglobulin G (IgG)/IgM antibody, hepatitis-C virus IgG antibody, hepatitis-B virus surface antigens and human immunodeficiency virus p24-antigen and antibodies were negative.

One year later (October 2009), the patient's conditions worsened due to onset of chest pain and dyspnea and, on hospital admission, echocardiography confirmed pericarditis with severe pericardial effusion; steroid therapy (as above) was resumed and after 4 months pericardiocentesis was performed.

In April 2010 the patient was again admitted to hospital for pericarditis relapse and knee-arthritis with important synovial effusion. Periocardiocentesis was repeated and $750 \mathrm{~cm}^{3}$ of serosanguineous fluid was drained; arthrocentesis was also performed. Fluid cultures were both negative for aerobic and anaerobic bacteria. Mycobacteria culture and Quantiferon test were negative for tuberculosis infection as well as cytologic test for malignant cells.

In order to find out the possible cause of pericarditis, a careful history ascertained that the patient had received influenza vaccine (Influvac ${ }^{\circ}$,trivalent, inactivated) $5-7$ days before the first admission; the patient reported reimmunization with influenza vaccine (unknown name and typology) also one year later, just some days before the second admission to hospital. In the absence of other possible causes (infectious diseases, autoimmune diseases, cancer, drugs), hypothesis of pericarditis and recurrence caused by influenza vaccine was therefore considered. Following the last hospital admission the cardiologist in charge recommended against influenza vaccinations in the future and the patient did not experience recurrence of pericarditis in the following 6 years of follow-up. 


\section{Discussion and conclusions}

Annual vaccination is an important public health measure to prevent influenza because influenza viruses change their antigenic characteristics frequently and may easily spread in the population [5-8]. In particular, elderly population ( $\geq 65$ years old) and individuals with underlying diseases have either higher risk of complications of influenza and death. In these categories, influenza vaccine reduces dramatically both influenza occurrence and the severity of the illness $[9,10]$. Moreover, influenza vaccine in older people is associated with a lower risk of cardiovascular events, especially in those with underlying cardiovascular risk factors (e.g. coronary disease) [11]. Annual immunization against influenza also reduces risk of death particularly in previously immunized [12] subjects.

Pericarditis typically presents with chest pain (> 85-90\% of cases), pericardial friction rub ( $\leq 33 \%$ of cases), ECG changes (up to $60 \%$ of cases), increased cardiac enzymes and markers of inflammation (i.e. C-reactive protein, erythrocyte sedimentation rate and white blood cell count). Recurrent pericarditis is diagnosed when a symptom-free interval of 4-6 weeks or longer separates the first episode of pericarditis. Recurrence occurs in $15-30 \%$ of cases after an initial episode, and may increase to $50 \%$ after a first recurrence in patients not treated with colchicine, particularly if treated with corticosteroids [13].

We searched MEDLINE in February 2017 for case reports/series, by combining the following key-words: "influenza", "vaccine", "immunization" and "pericarditis", without language restrictions. Six case reports (7 patients) of pericarditis after influenza immunization were identified: of these, 4 patients aged more than 60 years, mean time of symptom onset was 7 days, outcome was favorable in all the cases (recovery). According to the authors, a positive association between pericarditis and vaccine was defined in 4 cases, while 3 cases resulted with a "possible" association. In only one case, recurrence of pericarditis after influenza immunization reported, about 2 years after the first episode. Further details are shown in Table 1 . Only one case described a patient with recurrent pericarditis after influenza vaccination in two consecutive years [14]. Interestingly, Zanettini et al. compared 84 patients with pericarditis, divided into two groups; patients immunized with influenza vaccine, compared with patients not immunized, had a typical seasonal distribution with a peak in autumn, fewer comorbidities, less exuberant signs and symptoms, and clinical relief with NSAIDs use [15]. Considering the widespread use of influenza vaccination (approximately two of every five children and adults in the United States were vaccinated by early November 2016) [16], the occurrence of iatrogenic pericarditis is an extremely rare complication. However, in the light of the described event and the series reported by Zanettini et al., we cannot exclude that similar cases may be underestimated since the cause of more than a half pericarditis $(86.0 \%$ reported by Permanyer-Miralda et al., $78.0 \%$ reported by Zayas et al. and $83.2 \%$ reported by Imazio et al.) [17-19] remains undetermined.

We described a rare case of pericarditis following immunization, which did not meet the typical clinical and laboratory presentation. The underlying chronic diseases of the elderly patient (ischemic cardiomyopathy, permanent atrial fibrillation, chronic obstructive pulmonary disease and mild chronic kidney failure) do not fully explain pericarditis, although they probably contributed to its appearance (e.g. use of anticoagulant therapy). We cannot exclude that a recurrent viral infection could have caused the pericarditis episodes, because no specific viral studies were performed to systematically rule out viral etiologies of pericarditis. Nonetheless, hepatitis and HIV infections were excluded, as well as bacterial infections, since laboratory data and pericardial fluid culture were negative. These findings, together with positive rechallenge (re-administration one year after the first event with event re-occurrence) are key elements to define the association with influenza vaccine as "correlated" by

Table 1 MEDLINE search results for pericarditis after influenza vaccination

\begin{tabular}{|c|c|c|c|c|c|c|}
\hline Year & Age and sex & Adverse reaction & $\begin{array}{l}\text { Mean time } \\
\text { to onset }\end{array}$ & $\begin{array}{l}\text { Association according } \\
\text { to the author }\end{array}$ & Evolution & Ref. \\
\hline 1981 & $61 \mathrm{~F}$ & Recurrent pericarditis & 7 days & Yes & Favorable & [14] \\
\hline 1997 & $40 M$ & Pericarditis & 5 days & Yes & Favorable & {$[22]$} \\
\hline 2000 & $75 \mathrm{M} ; 40 \mathrm{M}$ & Pericarditis & 6 days; 5 days & Yes & Favorable (both) & [23] \\
\hline 2003 & $87 \mathrm{M}$ & Pericarditis & 5 days & Possible & Favorable & {$[24]$} \\
\hline 2004 & $68 \mathrm{~F}$ & Pericarditis and Guillain-Barré syndrome & 2 weeks & Possible & Favorable & {$[25]$} \\
\hline 2004 & $\approx 60$ (23 cases; $16 \mathrm{~F}$ and 7 M) & Pericarditis & Not reported & Yes & Favorable & {$[15]$} \\
\hline 2008 & $59 F$ & $\begin{array}{l}\text { Pericarditis, pancytopenia, autoimmune } \\
\text { haemolytic anemia, hepatitis and nephritis } \\
\text { due to systemic systemic lupus erythematosus } \\
\text { flare-up }\end{array}$ & 1 month & Possible & Favorable & {$[26]$} \\
\hline
\end{tabular}


WHO-AEFI (Adverse event Following Immunization) algorithm [20]. Moreover, the patient was monitored for the following 6 years during which influenza vaccination was not performed and no recurrence of pericarditis was reported (positive de-challenge). This is in line with Engler et al. [21] who strengthened the importance of active long-term surveillance.

In conclusion, although under-reporting can be supposed, the rarity of pericarditis after immunization does not affect the already established positive benefit-risk profile of influenza vaccine (and of vaccines in general). However, considering the high prevalence of pericarditis of undetermined origin, episodes of recent immunization should be highlighted in patient's history to support differential diagnosis.

\section{Abbreviations}

AEFI: Adverse event Following Immunization; ECG: Electrocardiogram; NSAIDs: Nonsteroidal anti-inflammatory drugs; WHO: World Health Organization

\section{Funding}

The Authors are supported by Institutional Research Funds (Ricerca Fondamentale Orientata). Riccardo Mei was supported by a fellowship ("assegno di ricerca") funded by Fondazione Parmiani, Bologna. There was no role of the funding body in the design of the study and collection, analysis and interpretation of data as well as in writing the manuscript.

\section{Availability of data and materials}

All data is contained within the manuscript and additional files.

\section{Authors' contributions}

ID conceived the study. ID and RM provided substantial contribution to data acquisition. RM, ER, ID, EP, FDP designed the study, provided substantial contribution to data analysis and interpretation. RM drafted the first version of the manuscript. ER, ID, EP, FDP critically revised the first draft for important intellectual content. All authors approved the final version to be published.

\section{Ethics approval and consent to participate}

Not applicable

\section{Consent for publication}

Written consent to publish all the personal and medical details included in the case report, as well as the accompanying images was obtained by the patient.

\section{Competing interests}

The authors declare that they have not competing interests. Dr. Fabrizio De Ponti is an Associate Editor for BMC Pharmacology and Toxicology.

\section{Publisher's Note}

Springer Nature remains neutral with regard to jurisdictional claims in published maps and institutional affiliations.

\section{Author details \\ ${ }^{1}$ Department of Medical and Surgical Sciences, Alma Mater Studiorum-University of Bologna, 40126 Bologna, Italy. ${ }^{2}$ Department of Experimental, Diagnostic and Specialty Medicine, Alma Mater Studiorum-University of Bologna, 40126 Bologna, Italy.}

Received: 18 October 2017 Accepted: 26 April 2018 Published online: 05 May 2018

\section{References}

1. Nalca A, Zumbrun EE. ACAM2000: the new smallpox vaccine for United States strategic National Stockpile. Drug Des Devel Ther. 2010;4:71-9. http:// www.ncbi.nlm.nih.gov/pubmed/20531961
2. Thanjan MT, Ramaswamy P, Lai WW, Lytrivi ID. Acute myopericarditis after multiple vaccinations in an adolescent: case report and review of the literature. Pediatrics. 2007;119:e1400-3. https://doi.org/10.1542/peds.2006-2605.

3. Vilchez RA, Fung JJ, Kusne S. Influenza a myocarditis developing in an adult liver transplant recipient despite vaccination: a case report and review of the literature. Transplantation. 2000;70:543-5.

4. Mittermayer $\mathrm{CH}$. Lethal complications of typhoid-cholera-vaccination. (case report and review of the literature). Beitr Pathol. 1976;158:212-24. http://www.ncbi.nlm.nih.gov/pubmed/985298

5. Uyeki TM. Preventing and controlling influenza with available interventions. N Engl J Med. 2014;370:789-91. https://doi.org/10.1056/NEJMp1400034.

6. Grohskopf LA, Sokolow LZ, Broder KR, Olsen SJ, Karron RA, Jernigan DB, Bresee JS. Prevention and control of seasonal influenza with vaccines., MMWR. Recomm. Reports. Morb Mortal Wkly Report Recomm Reports. 2016; 65:1-54. https://doi.org/10.15585/mmwr.rr6505a1.

7. C. Paules, K. Subbarao, Influenza., lancet (London, England). (2017). doi:10. 1016/S0140-6736(17)30129-0.

8. Treanor JJ. CLINICAL PRACTICE. Influenza vaccination. N Engl J Med. 2016; 375:1261-8. https://doi.org/10.1056/NEJMcp1512870.

9. Castilla J, Godoy P, Domínguez A, Martínez-Baz I, Astray J, Martín V, Delgado-Rodríguez $\mathrm{M}$, et al. Influenza vaccine effectiveness in preventing outpatient, inpatient, and severe cases of laboratory-confirmed influenza. Clin Infect Dis. 2013;57:167-75. https://doi.org/10.1093/cid/cit194.

10. Ehrlich HJ, Singer J, Berezuk G, Fritsch S, Aichinger G, Hart MK, El-Amin W, Portsmouth D, Kistner O, Barrett PN. A cell culture-derived influenza vaccine provides consistent protection against infection and reduces the duration and severity of disease in infected individuals. Clin Infect Dis. 2012;54:94654. https://doi.org/10.1093/cid/cir959.

11. Udell JA, Zawi R, Bhatt DL, Keshtkar-Jahromi M, Gaughran F, Phrommintikul A, Ciszewski A, Vakili H, Hoffman EB, Farkouh ME, Cannon CP. Association between influenza vaccination and cardiovascular outcomes in high-risk patients: a metaanalysis. JAMA. 2013;310:1711-20. https://doi.org/10.1001/jama.2013.279206.

12. Ahmed AE, Nicholson KG, Nguyen-Van-Tam JS. Reduction in mortality associated with influenza vaccine during 1989-90 epidemic. Lancet (London, England). 1995;346:591-5.

13. Adler Y, Charron P, Imazio M, Badano L, Barón-Esquivias G, et al. ESC Guidelines for the diagnosis and management of pericardial diseases, Eur. Heart J. 2015;36(2015)2921-2964. https://doi.org/10.1093/eurheartj/ehv318.

14. Streifler JJ, Dux S, Garty M, Rosenfeld JB. Recurrent pericarditis: a rare complication of influenza vaccination. Br Med J (Clin Res Ed). 1981;283:526-7.

15. Zanettini MT, Zanettini JO, Zanettini JP. Pericarditis. Series of 84 consecutive cases. Arq Bras Cardiol. 2004;82:360-9.

16. National Early-Season Flu Vaccination Coverage, United States, November 2016 | FluVaxView | Seasonal Influenza (Flu) |CDC, (n.d.); 2016.

17. Permanyer-Miralda G. Acute pericardial disease: approach to the aetiologic diagnosis. Heart. 2004;90:252-4.

18. Zayas R, Anguita M, Torres F, Gime D, Bergillos F, Ruiz M, Ciudad M, Gallardo $A$, Valles F. Incidence of specific etiology and role of methods for specific etiologic diagnosis of primary acute pericarditis. Am J Cardiol. 1995;75:37882. https://doi.org/10.1016/S0002-9149(99)80558-X.

19. Imazio $M$, Cecchi $E$, Demichelis $B$, Chinaglia A, lerna $S$, Demarie $D$, Ghisio A, Pomari F, Belli R, Trinchero R. Myopericarditis versus viral or idiopathic acute pericarditis. Heart. 2008:94:498-501. https://doi.org/10. 1136/hrt.2006.104067.

20. Causality assessment of an adverse event following immunization (AEFI) User manual for the revised WHO classification, March 2013.

21. Engler RJM, Nelson MR, Collins LC, Spooner C, Hemann BA, Gibbs BT, Atwood JE, Howard RS, Chang AS, Cruser DL, Gates DG, Vernalis MN, Lengkeek MS, McClenathan BM, Jaffe AS, Cooper LT, Black S, Carlson C, Wilson C, Davis RL. A prospective study of the incidence of myocarditis/ pericarditis and new onset cardiac symptoms following smallpox and influenza vaccination. PLoS One. 2015;10:e0118283. https://doi.org/10.1371/ journal.pone.0118283.

22. Desson JF, Leprévost M, Vabret F, Davy A. Acute benign pericarditis after anti-influenza vaccination. Presse Med. 1997;26:415. http://www.ncbi.nlm.nih. gov/pubmed/9137397

23. de Meester A, Luwaert R, Chaudron JM. Symptomatic pericarditis after influenza vaccination: report of two cases. Chest. 2000;117:1803-5.

24. Godreuil S, Delhaume O, Besset-Prat L, Blayac J-P, Peyriere H, Bonnet P. Acute haemorrhagic pericarditis following influenza vaccination. Presse Med. 2003;32:258-9. 
25. Kao C-D, Chen J-T, Lin K-P, Shan D-E, Wu Z-A, Liao K-K. Guillain-Barre syndrome coexisting with pericarditis or nephrotic syndrome after influenza vaccination. Clin Neurol Neurosurg. 2004;106:136-8. https://doi.org/10.1016/ j.clineuro.2003.11.002.

26. Stratta P, Cremona R, Lazzarich E, Quaglia M, Fenoglio R, Canavese C. Life-threatening systemic flare-up of systemic lupus erythematosus following influenza vaccination. Lupus. 2008;17:67-8. https://doi.org/10. $1177 / 0961203307083315$

Ready to submit your research? Choose BMC and benefit from:

- fast, convenient online submission

- thorough peer review by experienced researchers in your field

- rapid publication on acceptance

- support for research data, including large and complex data types

- gold Open Access which fosters wider collaboration and increased citations

- maximum visibility for your research: over $100 \mathrm{M}$ website views per year 